Vol 11, Issue 1, 2018

\title{
NEUROCHEMICAL ASSESSMENT AND BEHAVIORAL ROLE OF TUBEROINFUNDIBULAR PEPTIDE-39 IN ACUTE RESTRAINT STRESS-INDUCED DEPRESSION IN RATS
}

\author{
SANKAR V ${ }^{1}$, RAMANATHAN $M^{2}$, VENKATESH $G^{2 *}$ \\ ${ }^{1}$ Department of Pharmaceutics, PSG College of Pharmacy, Coimbatore, Tamil Nadu, India. ${ }^{2}$ Department of Pharmacology, PSG College of \\ Pharmacy, Coimbatore, Tamil Nadu, India. Email: gvenkatpharma@gmail.com
}

Received: 02 August 2017, Revised and Accepted: 26 October 2017

\section{ABSTRACT}

Objective: Tuberoinfundibular peptide of 39 (TIP39) is a potent agonist to the parathyroid hormone 2 receptor (PTH2R) abundantly expressed in brain. The current study focused to evaluate the role of TIP39 in acute restraint stress (ARS)-induced depression model.

Methods: Rats were exposed to ARS for $2 \mathrm{~h}$ to establish the depression and then subjected to open field and forced swim test (OFT and FST). TIP39 (1 and $10 \mathrm{nmol} / \mathrm{rat})$ and HYWH (1 nmol/rat) are a PTH2R antagonist which was infused through intracerebroventricular route. Diazepam $(2 \mathrm{mg} / \mathrm{kg}$, i.p) was utilized as reference standard.

Results: The results depict ARS significantly diminished the TIP39 expression in cerebral regions and causes depression-like behavior. TIP39 significantly decreased the immobility period in FST. In the OFT, TIP39 significantly increased the ambulatory activity and did not alter the rearing and grooming activity in comparison to ARS group. After TIP39 treatment, plasma noradrenaline levels were significantly increased, whereas the serotonin levels were unaltered. The corticosterone levels also decreased significantly. In rat brain tissues, TIP39 significantly reversed the abnormalities in glutamate and gamma-aminobutyric acid (GABA) level by ARS induction. In contrast, HYWH-treated rats did not show any significant variations in the neurochemical and behavioral parameters in comparison to ARS rats.

Conclusion: Our reports submitted that the primary evidence depicting the stimulation of TIP39 expression could modulate the monoaminergic, GABAergic, and glutaminergic release with the support of hypothalamic-pituitary-adrenal axis that can be produced an antidepressant-like effect evident with the interactive study.

Keywords: Tuberoinfundibular peptide of 39, Acute restraint stress, Hypothalamic-pituitary-adrenal axis, Glutamate, Gamma-aminobutyric acid, Noradrenaline.

(C) 2018 The Authors. Published by Innovare Academic Sciences Pvt Ltd. This is an open access article under the CC BY license (http://creativecommons. org/licenses/by/4. 0/) DOI: http://dx.doi.org/10.22159/ajpcr.2018.v11i1.21723

\section{INTRODUCTION}

The stress involved in the genesis of depression and is considered a paramount factor. It is estimated that depression will be the second most prevalent disease throughout the world [1]. Agreeing to a story from the WHO, approximately 300 million people all over the world suffer from depression and is forecast to grow by $15 \%$ by the year 2020 [2]. Tuberoinfundibular peptide of 39 (TIP39) is a neuroendocrine hormone, acting through parathyroid hormone 2 receptor (PTH2R) that potentially regulates hypothalamic-pituitary-adrenal (HPA) axis system. Studies proposed that TIP39 induces fos gene expression in the infralimbic cortex, preoptic area, lateral hypothalamus, lateral septum, and paraventricular thalamic nucleus; areas believed to be imperative in anxiety and depression [3]. Mice lacking TIP39 or PTH2R signalling significantly displayed increased anxiety and depression and also exhibited fear memory after exposure to an aversive event [4]. Many hypotheses postulated regarding the pathophysiological base of depression results from lack of monoamine neurotransmitter, (1) imbalance in glutamate and gamma-aminobutyric acid (GABA) level in brain (2), and over activation of the HPA axis. In depression, monoamine pathway is seen as the primary pathway embattled by most of the currently available depression therapies [5]. HPA axis which acts as a central part in mediating the response to various stressful stimuli [6]. Exposure of acute restraint stress (ARS) can activate the HPA axis, resulting in higher blood levels of corticosterone (CORT), and dysregulates circadian rhythm of CORT secretion. This cascade of the event finally stimulates the overexpression of glucocorticoids receptors in the hippocampus, which in turn cut the size and functionality of hippocampus. The revival of HPA axis activity has been seen as an indicator of improvement in depression. Studies also proposed that therapy of depression based on the serotonergic and noradrenergic mechanism effectively controls the channels of the HPA axis function [7]. In this setting, extensive research suggests that studies on depression have shifted from monoamines toward other mechanisms, including glutaminergic neurotransmission [8]. About $80 \%$ of neurons in the brain found to have glutamate, which is considerably more than monoamines. Glutamate is the major excitatory neurotransmitter which is in a balance with inhibitory neurotransmitter GABA [9]. Emerging evidence hold up the deficits of GABAergic transmission is also a major cause for stress-induced depression and also found that downstream modification in GABAergic activity with the currently available monoaminergic antidepressants, suggesting that deregulation of glutamate and GABA system is involved in the pathogenesis of depression [10]. Although TIP39 has possible relation to the pathogenesis of depression, no direct evidence to authenticate the functional correlation of TIP39 and depression caused by stress. With the hold of optimistic regulation of TIP39, for the first time, this study points toward a specific neurotransmitter involvement in ARS rats, with the support of PTH2R agonist and antagonist.

\section{MATERIALS}

Chemicals and reagents

TIP39 peptide purchased from Life Technologies Pvt Ltd., India. HYWH, PTH2R antagonist synthesized from Biomolecules Midwest Inc., USA. Serotonin (5HT), L-glutamic acid, and GABA were purchased from Sigma, USA. Noradrenalin (NA) was received as gift sample from Neon lab, India. All other chemical, reagents, and solvents were of analytical grade. 


\section{Animals}

Male Sprague-Dawley rats (150-200 g) were obtained from PSG IMS\&R (205/2013/IAEC). Experiment was performed according to the experimental protocol approved by the institutional animal ethics committee (IAEC). Rats were maintained in a separate cage ( 6 animals per cages) with the standard diet. Animals were housed under room temperature $\left(25 \pm 2^{\circ} \mathrm{C}\right), 12 / 12 \mathrm{~h}$ light-dark cycle, and humidity $(55 \pm 5 \%)$ according to the CPCSEA guidelines and guide for the care and use of laboratory animals.

\section{Surgical procedure and drug treatment}

TIP39 peptide was infused through intracerebroventricular route over $5 \mathrm{~min}$. Stereotaxic surgery was made 7 days before the test and standard drug administration. Rats were anesthetized with ketamine ( $80 \mathrm{mg} / \mathrm{kg}$, i.m.) and xylazine (10 mg/kg, i.m.). Guide cannulae (Stainless steel (OD 0.64×ID 0.45) RWD Life Science Co., Ltd., China) was implanted in the right lateral ventricle at pre-established coordinates, anteroposterior, $0.2 \mathrm{mM}$ from bregma, lateral, $1.5 \mathrm{mM}$, and vertical, 4.2 $\mathrm{mM}$ and kept under controlled temperature in an individual cages [11].

\section{Behavior study}

The animal behavior was assessed in an open-field apparatus made of plywood, consisted of a floor $(96 \times 96 \mathrm{~cm})$ with high walls. The entire apparatus was painted black except for $6 \mathrm{~mm}$ thick white lines which divided the floor into 16 squares. Experimental animals were placed in the center of an open box and allowed for free exploration. Behavioral parameters were quantified, such as ambulation, rearing, and grooming for $5 \mathrm{~min}$ [12]. With the slight modification, forced swim test (FST) was conducted. Rats were allowed to swim individually in a transparent glass vessel $(45 \mathrm{~cm} \times 12 \mathrm{~cm} \times 45 \mathrm{~cm})$ with water filled to $30 \mathrm{~cm}$ [13]. $24 \mathrm{~h}$ before start of the test session, animals were allowed to swim for $10 \mathrm{~min}$ as training. The duration of immobility was observed for $5 \mathrm{~min}$ in a 6 min test session. Rats were considered as immobile when they made no attempts to escape.

\section{HT and NA estimation in plasma}

Blood samples were collected and mixed with $10 \%$ sodium citrate solution and then centrifuged at $3000 \mathrm{rpm}$ for $10 \mathrm{~min}$. Supernatant liquid was collected and stored at $-10^{\circ} \mathrm{C}$ for estimation of $5 \mathrm{HT}$ and NA by high-performance liquid chromatography (HPLC) systems using Electrochemical detector (Shimadzu LC) [14].

\section{Glutamate and GABA estimation in brain tissue}

Brain samples were isolated and homogenized in $0.1 \mathrm{~N} \mathrm{HCl}$ in $80 \%$ ethanol ( $10 \mathrm{mg}$ tissue $/ 200 \mu \mathrm{l}$ ) and centrifuged at $4500 \mathrm{rpm}$ for $20 \mathrm{~min}$ at $25^{\circ} \mathrm{C}$. The supernatant was collected and estimated by HPTLC (CAMAG version 1.3.4, USA) at $486 \mathrm{~nm}$. Standard solutions of L-glutamic acid (20-200 ng/spot) and GABA (5-80 ng/spot) were prepared for plotting the calibration curve [15].

\section{Estimation of CORT}

Immediately after the stress protocol, animals were sacrificed by decapitation and blood was transferred to sodium citrate and centrifuged at $2000 \mathrm{rpm}$ for $20 \mathrm{~min}$. Plasma was separated and aliquots were stored at $-80^{\circ} \mathrm{C}$ for CORT estimation by HPLC/UV system according to the study of Ahmad et al. [16].

Measurement of TIP39 expression by polymerase chain reaction The cells were lysed using TRI reagent (Sigma-Aldrich), and the total RNA was extracted and quantified by NanoDrop (Thermo Scientific Wilmington, DE, USA) and whose 260/280 ratio found $>1.8$ were used for cDNA conversion (Applied Biosystems, USA). Primer sequences were synthesized at Sigma-Aldrich, MO, USA. The primer sequence is Forward: 5'-GCTTCTGGGTGTGATGGTGA-3, Reverse: 5'-AGCAGCAAAAGCAGCAGCAG-3'. PCR reactions were run in qPCR (Applied Biosystems, USA) system. Reactions were initiated with denaturation at $95^{\circ} \mathrm{C}$ for $30 \mathrm{~s}$, followed by 40 cycles of two-step reaction, denaturation at $95^{\circ} \mathrm{C}$ for $5 \mathrm{~s}$, and annealing and extension for $30 \mathrm{~s}$ [17].

\section{Statistical analysis}

Data were expressed as mean \pm SEM and one-way analysis of variance followed by post hoc analysis. Tukey's multiple comparison tests was used to analyze the data. A p $<0.05$ was considered as statistically significant. Data were analyzed using Graph Pad Prism, 4.03 (La Jolla, CA. USA).

\section{RESULTS}

Effect of PTH2R agonist and antagonist in open-field exploratory behavior test

As shown in Table 1, no significant changes in open-field exploratory behavior were observed following either TIP39 or HYWH administration in ARS rats. ARS-inducted rats exhibited significantly decreased ambulation $(F(6,35)=4.2, p<0.01)$, rearing $(F(6,35)=7.08$, $\mathrm{p}<0.001)$, and increased grooming $(\mathrm{F}(6,35)=2.81, \mathrm{p}<0.05)$ response compared to control and diazepam $2 \mathrm{mg} / \mathrm{kg}$ treated rats. Treatment with TIP39 ( 1 and $10 \mathrm{nmol} / \mathrm{rat}$ ) and TIP39+HYWH $(1 \mathrm{nmol} / \mathrm{rat})$ did not show significant changes in rearing $(F(6,35)=1.52, p>0.05)$ and grooming $(F(6,35)=0.09, p>0.05)$ as compared to the ARS rats but not in ambulation $(\mathrm{F}(6,35)=1.8, \mathrm{p}<0.05)$ on TIP39 ( 1 and $10 \mathrm{nmol} / \mathrm{rat})$ treatment.

\section{Effect of PTH2R agonist and antagonist in FST}

The obtained results showed that ARS group significantly $(\mathrm{F}(6,35)=13.61, \mathrm{p}<0.01)$ increased the immobility time as compared to control and diazepam $2 \mathrm{mg} / \mathrm{kg}$ treated rats. TIP39 both doses, i.e., 1 and $10 \mathrm{nmol} / \mathrm{rat}$, significantly decreased immobility time as compared to the ARS group $(F(6,35)=5.61, p<0.05, F(6,35)=9.02$, $\mathrm{p}<0.01)$. Treatment of HYWM ( $1 \mathrm{nmol} / \mathrm{rat})$ along with TIP39 (1 and $10 \mathrm{nmol} / \mathrm{rat}$ ) did not significantly alter the total immobility time in the FST as comparable to ARS group $(F(6,35)=1.61, p>0.05, F(6,35)=2.1$, $\mathrm{p}>0.05$ ) (Table 1).

Effect of PTH2 R agonist and antagonist in plasma 5HT and NA level As shown in Fig. 1a and b, ARS group showed significant decreased level of plasma 5HT $(\mathrm{F}(6,35)=10.1, \mathrm{p}<0.001)$ and $\mathrm{NA}(\mathrm{F}(6,35)=13.2$, $\mathrm{p}<0.001$ ) as compared to control group. Treatment with TIP39 (1 and $10 \mathrm{nmol})$ significantly increased the NA level in plasma $(\mathrm{F}(6,35)=4.2$, $\mathrm{p}<0.01, \mathrm{~F}(6,35)=6.1, \mathrm{p}<0.01)$, whereas TIP39 (1 and $10 \mathrm{nmol} /$ rat $)+$ HYWH $(1 \mathrm{nmol} / \mathrm{rat})$ did not show significant changes in NA level as compared to the ARS rats. In contrast, treatment with TIP39 1 and $10 \mathrm{nmol}(\mathrm{F}(6,35)=0.46, \mathrm{p}>0.72)$ and TIP $39+\mathrm{HYWH}(1 \mathrm{nmol} / \mathrm{rat})$ did not show significant changes in plasma $5 \mathrm{HT}$ level as compared to the ARS rats $(F(6,35)=1.06, p>0.05)$.

Effect of PTH2R agonist and antagonist in brain glutamate and GABA activity

As shown in Fig. 1c and d, ARS exposure caused a significant increase of glutamate $(F(6,35)=15.6, p<0.001)$ and decrease of GABA $(F(6,35)=11.3, p<0.001)$ activity in brain tissue when compared with control group. Diazepam $2 \mathrm{mg} / \mathrm{kg}$ treated rats with TIP39 doses, i.e. 1 and $10 \mathrm{nmol}$ significantly decreased the glutamate $(\mathrm{F}(6,35)=2.8$, $\mathrm{p}<0.05, \mathrm{~F}(6,35)=3.6, \mathrm{p}<0.01)$ and significantly increased the GABA $(F(6,35)=3.16, p<0.05, F(6,35)=5.3, p<0.01)$ activity in brain, whereas TIP39+HYWH (1 nmol/rat) did not show significant changes in glutamate and GABA activity compared to the ARS rats $(\mathrm{F}(6,35)=1.5$, $\mathrm{p}>0.05)$.

\section{Effect of PTH2R agonist and antagonist in CORT level}

ARS group significantly $(F(6,35)=15.2, \quad p<0.001)$ increased the CORT as compared to control group. Diazepam at the dose of $2 \mathrm{mg} / \mathrm{kg}$ significantly decreased the CORT when compared to ARS group $(F(6,35)=17.1, p<0.001)$. Similarly, TIP39 both doses, i.e., 1 and $10 \mathrm{nmol} / \mathrm{rat}$, significantly decreased CORT as compared to the ARS group $(F(6,35)=8.61, p<0.01$ and $F(6,35)=13.02),(p<0.001)$. Treatment of HYWM (1 nmol/rat) along with TIP39 ( 1 and $10 \mathrm{nmol} / \mathrm{rat}$ ) did not significantly alter the CORT in the plasma $(F(6,35)=1.81, p>0.05$ and $\mathrm{F}(6,35)=2.6), \mathrm{p}>0.05$ ) as comparable to ARS group (Fig. 2). 
Table 1: Effect of TIP39 treatment on OFT and FST in ARS rats

\begin{tabular}{|c|c|c|c|c|}
\hline \multirow[t]{2}{*}{ Groups } & \multicolumn{3}{|c|}{ Open field exploratory behavior } & \multirow{2}{*}{$\begin{array}{l}\text { Behavioral despair activity } \\
\text { Immobility time }\end{array}$} \\
\hline & Ambulation & Grooming & Rearing & \\
\hline Control\# & $39 \pm 2.2$ & $13.5 \pm 2.8$ & $22.8 \pm 3.1$ & $81.5 \pm 13.1$ \\
\hline Diazepam $2 \mathrm{mg} / \mathrm{kg}$ & $27.3 \pm 2 * * *$ & $15.8 \pm 1.6^{* * *}$ & $18.6 \pm 2.5^{* * *}$ & $109.8 \pm 15.8^{* *}$ \\
\hline TIP39 $1 \mathrm{nmol} / \mathrm{rat}$ & $23.8 \pm 1.4^{*}$ & $22.3 \pm 1.8$ & $15 \pm 2$ & $135.1 \pm 13.7^{*}$ \\
\hline TIP39 $1 \mathrm{nmol}+\mathrm{HYWH} 1 \mathrm{nmol} / \mathrm{rat}$ & $15 \pm 1.4$ & $22.6 \pm 1.8$ & $13.6 \pm 1.6$ & $162 \pm 15.2$ \\
\hline TIP39 $10 \mathrm{nmol} / \mathrm{rat}$ & $25.6 \pm 2 * *$ & $22.3 \pm 1.6$ & $14.8 \pm 2.1$ & $119.5 \pm 10.6^{* *}$ \\
\hline TIP39 $10 \mathrm{nmol}+\mathrm{HYWH} 1 \mathrm{nmol} / \mathrm{rat}$ & $17.8 \pm 1.8$ & $21.1 \pm 1.7$ & $13.3 \pm 1.6$ & $162.6 \pm 18.6$ \\
\hline
\end{tabular}

Values are expressed in mean \pm SD, $n=6$. One-way ANOVA followed by post hoc analysis. Tukey's multiple comparison tests. \#, \#\#, \#\#\#denotes ARS versus control rats $\mathrm{p}<0.05, \mathrm{p}<0.01$, and $\mathrm{p}<0.001$, respectively. $* * *, * * *$ treatment versus ARS, $\mathrm{p}<0.05, \mathrm{p}<0.01$, and $\mathrm{p}<0.001$, respectively. TIP39: Tuberoinfundibular peptide of 39 , ARS: Acute restraint stress, FST: Forced swim test, OFT: Open field test, SD: Standard deviation, ANOVA: Analysis of variance

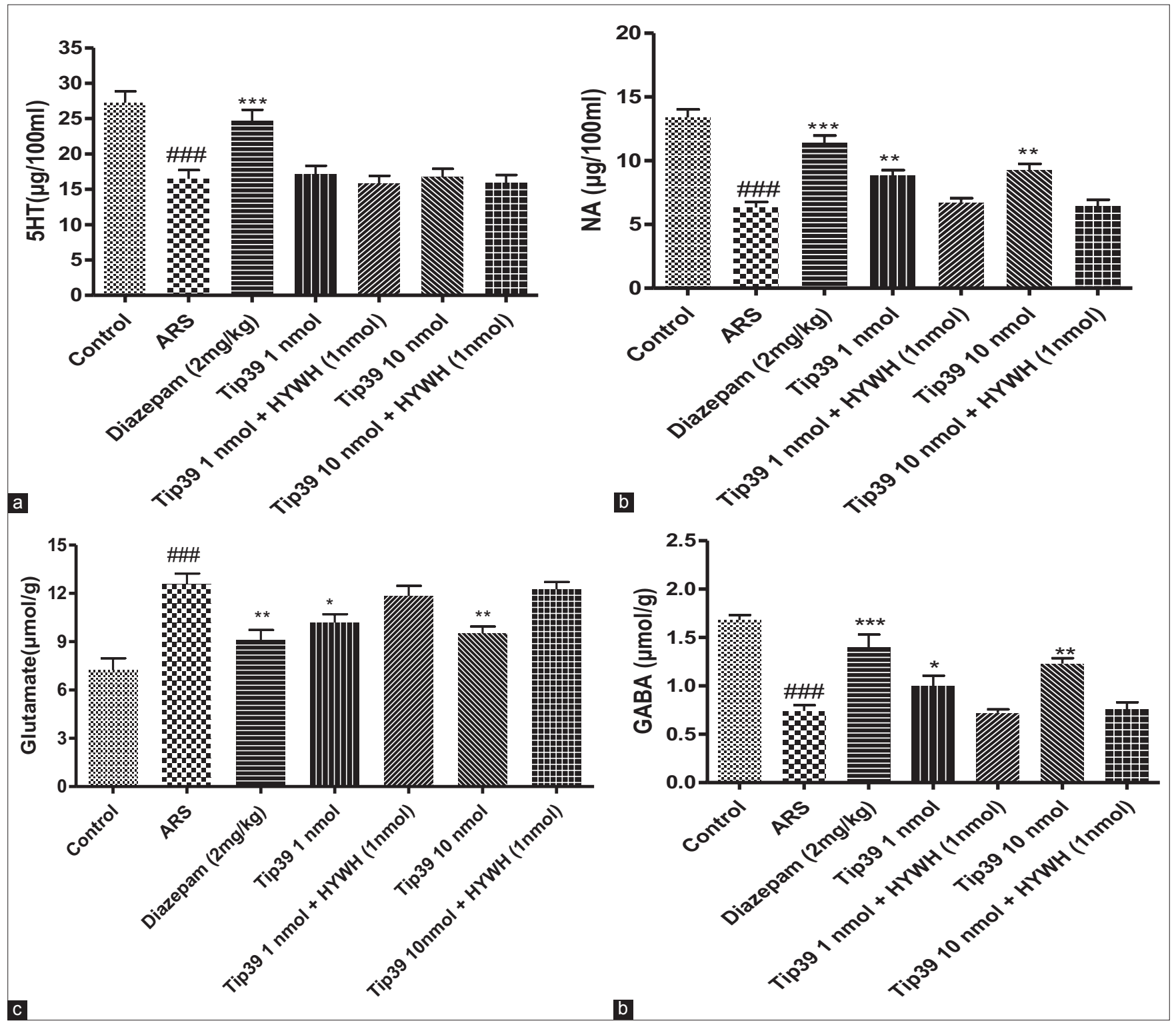

Fig. 1: (a-d) Effect of tuberoinfundibular peptide-39 treatment on neurotransmitter level in acute restraint stress (ARS) rats. Values are expressed in mean \pm standard deviation, $\mathrm{n}=6$. One-way analysis of variance followed by post hoc analysis Tukey's multiple comparison test. \#\#\#denotes ARS versus control, $p<0.001$. $^{* * *}, * * *$ denotes treatment versus ARS, $p<0.05, p<0.01$ and $p<0.001$, respectively.

Estimation of TIP39 expression in rat brain by polymerase chain reaction

On $2 \mathrm{~h}$ of ARS induction, rats have shown significant decrease of TIP39 gene expression in brain tissue as compared to normal rats
$(F(2,15)=3.9, p<0.01)$. In contrast, on half an hour of ARS decreased expression of TIP39 gene was observed as compared to normal rats, but there were no significant $(F(2,15)=2.16, p>0.05)$ differences exhibited (Fig. 3). 


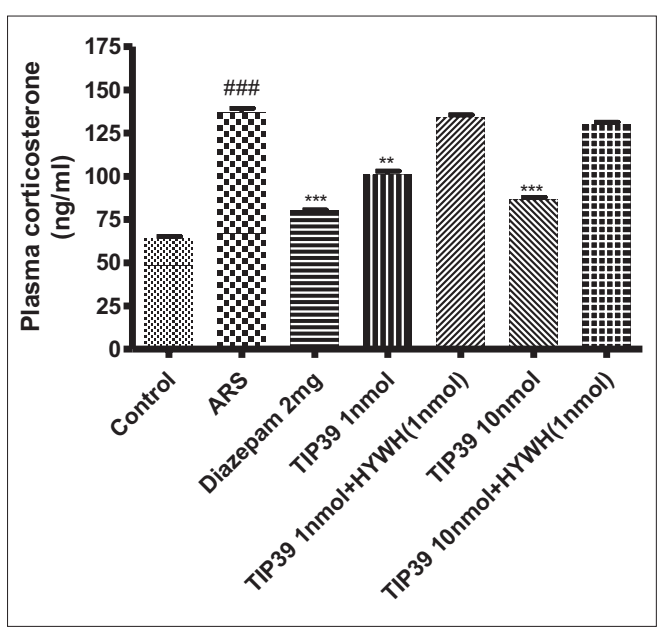

Fig. 2: Effect of tuberoinfundibular peptide-39 on plasma corticosterone in CUMS rats. Values are expressed in mean \pm standard deviation, $\mathrm{n}=6$. One-way analysis of variance followed by post hoc analysis Tukey's multiple comparison test.

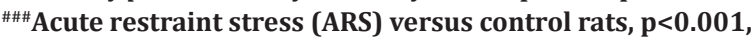
respectively. ${ }^{* * * * * *}$ Treatment versus ARS rats, $\mathbf{p}<0.01$ and $p<0.001$, respectively

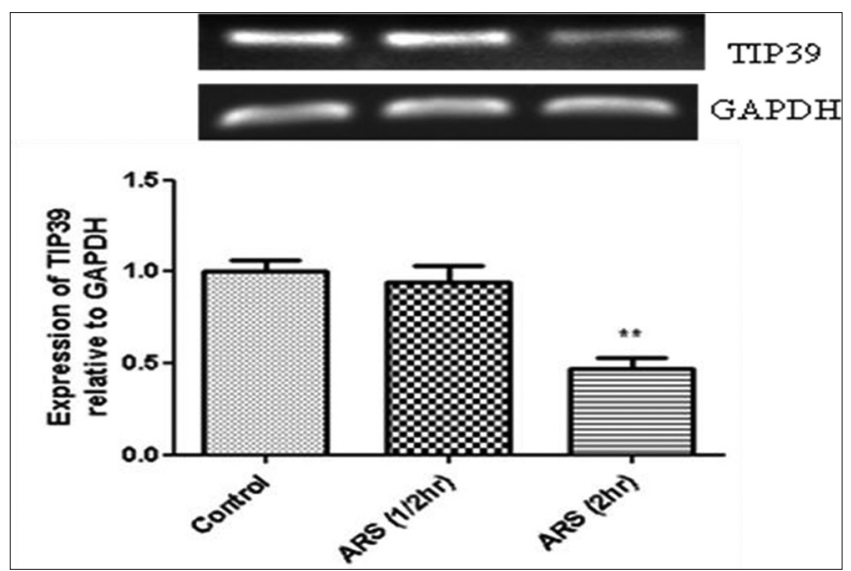

Fig. 3: Expression of tuberoinfundibular peptide of 39 in the brain by polymerase chain reaction. Values are expressed in mean \pm standard deviation, $n=6$. One-way analysis of variance followed by post hoc analysis Tukey's multiple comparison test. **Denotes control versus acute restraint stress, $\mathbf{p}<0.001$

\section{DISCUSSION}

Bounteous evidence demonstrated that stress is the key factor in the pathogenesis of neuropsychiatric disorders including anxiety, depression, cognitive damage, insomnia, and anorexia [18]. In the present study, we demonstrated that ARS exposure selectively decreased TIP39 expression in rat brain and that could mimic depression-like behavior. TIP39 could activate monoamine like noradrenaline but not serotonin level in plasma and we showed evidence for a GABA role in terms of controlling the glutaminergic action.

In a pilot study, TIP39 expression was examined in normal and stressed rats. The animal received $30 \mathrm{~min}$ of ARS did not establish the significant decrease in TIP39 expression as compared to control group. In contrast, animal received $2 \mathrm{~h}$ of ARS significantly decreased the TIP39 expression, meant that severe stress has vital relation with the PTH2-TIP39 system. Hence, we had chosen $2 \mathrm{~h}$ of ARS model to assess the role of TIP39 in depressive rats. In the same work, we further confirmed the relationship between a PTH2R-TIP39 system and neurotransmitter release during stress by administering PTH2 agonist (TIP39) and with the PTH2 antagonist (HYWH). Moreover, our determinations are consistent with the study of Usdin et al., which indicated that TIP39/PTH2R knockout mice showed depression-like behavior [4].

An effect of TIP39 at the immobility time was studied in FST model which is been really accurate and takes in the greater pharmacological sensitivity [19]. TIP39 at doses of 1 and $10 \mathrm{nmol} / \mathrm{rat}$ significantly decreased the duration of immobility. However, HYWH-treated animal did not demonstrate any real growth as compared to control group, suggesting that TIP39 might potentially have antidepressant-like activity. This is the first interactive study that verifies the antidepressant effect of TIP39 in ARS rats. The present data were consistent with the report of LaBuda et al. which indicates that TIP39 can decrease the duration of immobility in the FST model [3].

The FST combined with the open field test (OFT) can separate locomotorstimulant drugs from antidepressant drugs [20]. In our work, ARS significantly decreased ambulation and rearing and increased grooming response, lets on less exploratory, lack of interest and anxiety-like deportment, which are raw to the monoaminergic system, in accordance with the previous report [21]. Acute ICV administration of TIP39 did not alter the open-field exploratory activity significantly except ambulatory behavior compared to ARS rats, indicating that TIP39 improved the decreased locomotor activity, simply had no psychostimulant effects. The abovementioned two different behavioral investigations provided convincing evidence to the antidepressant activity of TIP39.

Increased CORT level could cause depression-like behaviors that decrease hippocampal neurogenesis [22]. Our results showed that decreased TIP39 expression could increase the serum CORT, which suggests CORT might be involved in TIP39-related depression-like behavior. A higher level of CORT and hyperactivity of HPA axis has been implicated in the development of depression. In the present study, the ARS group showed a substantial lift in the CORT level as compared to the control group, which was reversed after TIP39 administration, dosedependently. In contrast, our study report is inconsistent with LaBuda et al., which indicated that increased plasma CORT level after TIP39 infusion in the paraventricular hypothalamic nucleus (PVN) region [3]. This might be ascribable to the deviation in the volume of stress applied. Nevertheless, the detailed mechanisms still need to be careful in future research. Many written reports have publicized that ventral hypothalamus (VH) had glutamatergic input to the PVN, while PVN is liable for coordinating the regulation of the HPA axis [23]. Consequently, adaptations of CORT and ACTH levels may be interrelated with the PVN, which is regulated by the VH directly. Interestingly, neuroanatomical studies implicated that high-density TIP39 fibers project widely in many limbic areas, including the PVN and several hypothalamic nuclei. Earlier studies also implicated that TIP39 peptide potentially modulates the natural process of the HPA axis during stressful condition [24].

Depression invariably accompanied by the reduction in 5-HT, NE, and DA level in the blood and brain tissues which are in close relation with symptoms of depression [25]. In the present work, we found that NE and $5 \mathrm{HT}$ were significantly decreased in the ARS group compared to control group. TIP39 administration significantly increased the NE content when compared to ARS group which was not seen in HYWHtreated groups. In contrast, 5-HT levels were not significantly different among the treatment and ARS groups, indicating that 5-HT levels in the whole brain were not significantly impressed. Thus, our study demonstrating that elevation of $\mathrm{NE}$ in the treatment group might be a cause for increasing ambulatory behavior in OFT. An earlier study also has revealed that TIP39/PTH2-R system potentially acting through central noradrenergic signalling pathway [26]. With the aforementioned resolution, we could infer that the antidepressantlike effect of TIP39 may be associated with modulation of the central noradrenergic pathway.

Finding efficient therapy in challenging depression is very difficult may be due to diversity in the origin of mood and mental disorders associated 
with different genetic and environmental factors. Recent years, studies on depression have focused to a greater extent on the glutaminergic role rather than the monoamines. Studies revealed that high level of brain and plasma glutamate was found in the patient with depression and also established that inhibition of glutamatergic neurotransmission was strongly correlated with the therapeutic action of a majority of antidepressant drugs [27]. Interestingly, in whole brain tissue, TIP39 significantly reduced the glutamate level as compared to ARS rats. In contrast, GABA content was significantly increased as compared to ARS rats, which were not observed in rats treated with HYWH. Mathew et al. stating that imbalance between the glutamate and GABA content in the brain can cause depression-like behavior which is coherent with the present study. These reports point toward the importance of TIP39 in regulating the glutaminergic and GABAergic system. However, our study report supports the previous study implicated that TIP39 peptide can regulate hypothalamic glutaminergic and inhibitory GABAergic neuron in the cerebral region [28]. Recent studies have reported that, besides the limbic area, TIP39 is abundantly expressed in other brain regions also [29]. Hence, our study suggests that the curative role of TIP39 needs to be explored in other brain areas, equally well. This study provided the first evidence indicating that stimulating TIP39 expression can bring about an antidepressant-like effect by modulating the monoaminergic, GABAergic, and glutaminergic release with the support of HPA axis.

\section{ACKNOWLEDGMENTS}

We thank Mr. Abdul Khayum for English proof reading and editing. We acknowledge the Management of PSG College of Pharmacy for granting permission to conduct the study.

\section{REFERENCES}

1. Budni J, Zomkowski AD, Engel D, Santos DB, dos Santos AA, Moretti $\mathrm{M}$, et al. Folic acid prevents depressive-like behavior and hippocampal antioxidant imbalance induced by restraint stress in mice. Exp Neurol 2013;240:112-21.

2. Santosh P, Venugopl R, Nilakasha S, Kunjbihari S, Mangala L. Antidepressant activity of methanolic extract of Passiflora foetida leaves in mice. Int J Pharm Pharm Sci 2011;3:6-9.

3. LaBuda CJ, Dobolyi A, Usdin TB. Tuberoinfundibular peptide of 39 residues produces anxiolytic and antidepressant actions. Neuroreport 2004; 15:881-5.

4. Coutellier L, Usdin TB. Enhanced long-term fear memory and increased anxiety and depression-like behavior after exposure to an aversive event in mice lacking TIP39 signaling. Behav Brain Res 2011;222:265-9.

5. Aihara M, Ida I, Yuuki N, Oshima A, Kumano H, Takahashi K, et al. HPA axis dysfunction in unmedicated major depressive disorder and its normalization by pharmacotherapy correlates with alteration of neural activity in prefrontal cortex and limbic/paralimbic regions. Psychiatry Res 2007;155:245-56.

6. Barden N. Implication of the hypothalamic-pituitary-adrenal axis in the physiopathology of depression. J Psychiatry Neurosci 2004;29:185-93.

7. Nikisch G. Involvement and role of antidepressant drugs of the hypothalamic-pituitary-adrenal axis and glucocorticoid receptor function. Neuro Endocrinol Lett 2009;30:11-6.

8. Catena-Dell'Osso M, Fagiolini A, Rotella F, Baroni S, Marazziti D. Glutamate system as target for development of novel antidepressants. CNS Spectr 2013;18:188-98.

9. Mathew SJ, Keegan K, Smith L. Glutamate modulators as novel interventions for mood disorders. Rev Bras Psiquiatr 2005;27:243-8.
10. Hashimoto K. Emerging role of glutamate in the pathophysiology of major depressive disorder. Brain Res Rev 2009;61:105-23.

11. Santos GA, Pereira VD, Roman EA, Ignacio-Souza L, Vitorino DC, de Moura RF, et al. Hypothalamic inhibition of acetyl-coA carboxylase stimulates hepatic counter-regulatory response independent of AMPK activation in rats. PLoS One 2013;8:e62669.

12. Pawar DB, Marathe PA, Rege NN. Antidepressant activity of aqueous extracts of fruits of Terminalia chebula and Phyllanthus emblica in behavioral models of depression: Involvement of monoaminergic system. Int J Pharm Pharm Sci 2014;6:615-20.

13. Devil T, Das S. Evaluation of the protective effect of ethanolic extract of leaves of Punica granatum linn. On forced swimming induced chronic fatigue syndrome in mice. Int J Pharm Pharm Sci 2017;9:207-12.

14. Parrot S, Neuzeret PC, Denoroy L. A rapid and sensitive method for the analysis of brain monoamine neurotransmitters using ultra-fast liquid chromatography coupled to electrochemical detection. J Chromatogr B Analyt Technol Biomed Life Sci 2011;879:3871-8.

15. Tshibangu DS, Divakar S, Ramanathan M, Syamala GG, Ngbolua K, Mudogo V, et al. In vitro Screening of the leaf extracts from Gardenia ternifolia (Forest Gardenia) for their Anticancer Activity. J Complement Alternat Med 2016;1:1-7.

16. Badenhorst NJ, Brand L, Harvey BH, Ellis SM, Brink CB. Long-term effects of pre-pubertal fluoxetine on behaviour and monoaminergic stress response in stress-sensitive rats. Acta Neuropsychiatr 2017;29:222-35

17. Darshit BS, Ramanathan M. Activation of AKT1/GSK-3??/??Catenin???TRIM11/Survivin Pathway by Novel GSK-3?? Inhibitor Promotes Neuron Cell Survival: Study in Differentiated SH-SY5Y Cells in OGD Model. Mol Neurobiol 2016;53:6716-29.

18. Subakanmani S, Umadevi P. Evaluation of anxiolytic potential of ethanolic extract Hypericum hookerianum in stress induced swiss albino mice. Int Res J Pharm 2012;3:219-25.

19. Paul IA, Skolnick P. Glutamate and Depression: Clinical and Preclinical Studies. Ann N Y Acad Sci 2003;1003:250-72.

20. Steru L, Chermat R, Thierry B, Simon P. The tail suspension test: A new method for screening antidepressants in mice. Psychopharmacology (Berl) $1985 ; 85: 367-70$

21. Joca SR, Padovan CM, Guimarães FS. Activation of post-synaptic 5-HT1A receptors in the dorsal hippocampus prevents learned helplessness development. Brain Res 2003;978:177-84.

22. Freitas AE, Egea J, Buendia I, Gómez-Rangel V, Parada E, Navarro E, et al. Agmatine, by improving neuroplasticity markers and inducing nrf2, prevents corticosterone-induced depressive-like behavior in mice. Mol Neurobiol 2016;53:3030-45.

23. Ulrich-Lai YM, Herman JP. Neural regulation of endocrine and autonomic stress responses. Nat Rev Neurosci 2009;10:397-409.

24. Dobolyi A, Palkovits M, Usdin TB. Expression and distribution of tuberoinfundibular peptide of 39 residues in the rat central nervous system. J Comp Neurol 2003;455:547-66.

25. Nutt DJ. Relationship of neurotransmitters to the symptoms of major depressive disorder. J Clin Psychiatry 2008;69 Suppl E1:4-7.

26. Coutellier L, Logemann A, Kuo J, Rusnak M, Usdin TB. TIP39 modulates effects of novelty-induced arousal on memory. Genes Brain Behav 2011;10:90-9.

27. Mathews DC, Henter ID, Zarate CA. Targeting the glutamatergic system to treat major depressive disorder: Rationale and progress to date. Drugs 2012;72:1313-33.

28. Dimitrov EL, Kim YY, Usdin TB. Regulation of hypothalamic signaling by tuberoinfundibular peptide of 39 residues is critical for the response to cold: A novel peptidergic mechanism of thermoregulation. J Neurosci 2011:31:18166-79.

29. Wang T, Palkovits M, Rusnak M, Mezey E, Usdin TB. Distribution of parathyroid hormone-2 receptor-like immunoreactivity and messenger RNA in the rat nervous system. Neuroscience 2000;100:629-49. 